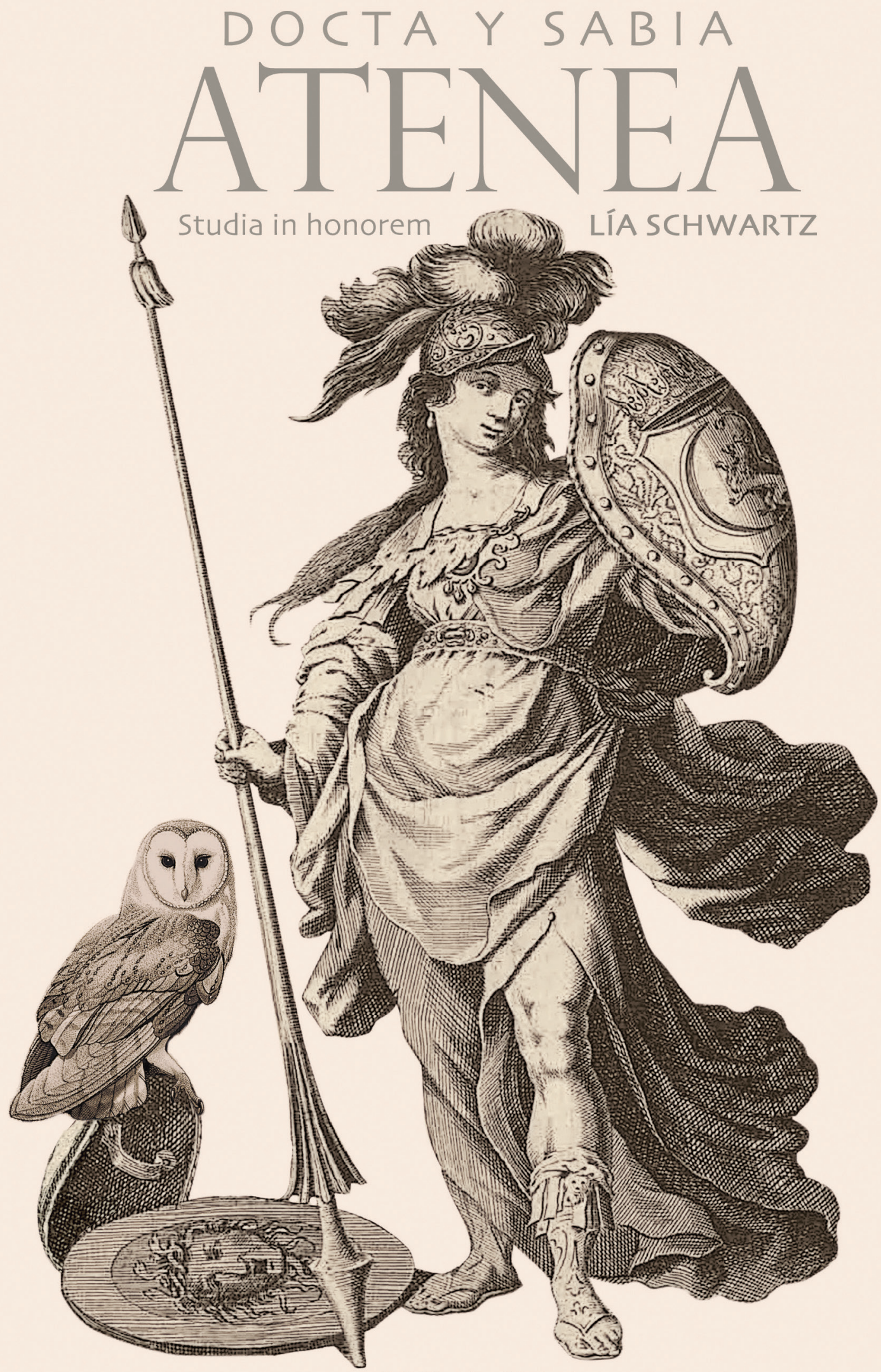

Edición al cuidado de:

SAGRARIO LÓPEZ POZA, NIEVES PENA SUEIRO, MARIANO DE LA CAMPA, ISABEL PÉREZ CUENCA, SUSAN BYRNE Y ALMUDENA VIDORRETA 



\section{DOCTA Y SABIA ATENEA Studia in honorem Lía Schwartz}

Edición al cuidado de:

Sagrario López Poza, Nieves Pena Sueiro, Mariano de la Campa, Isabel Pérez Cuenca, Susan Byrne y Almudena Vidorreta

A Coruña, 2019 

Profesora Lía Schwartz

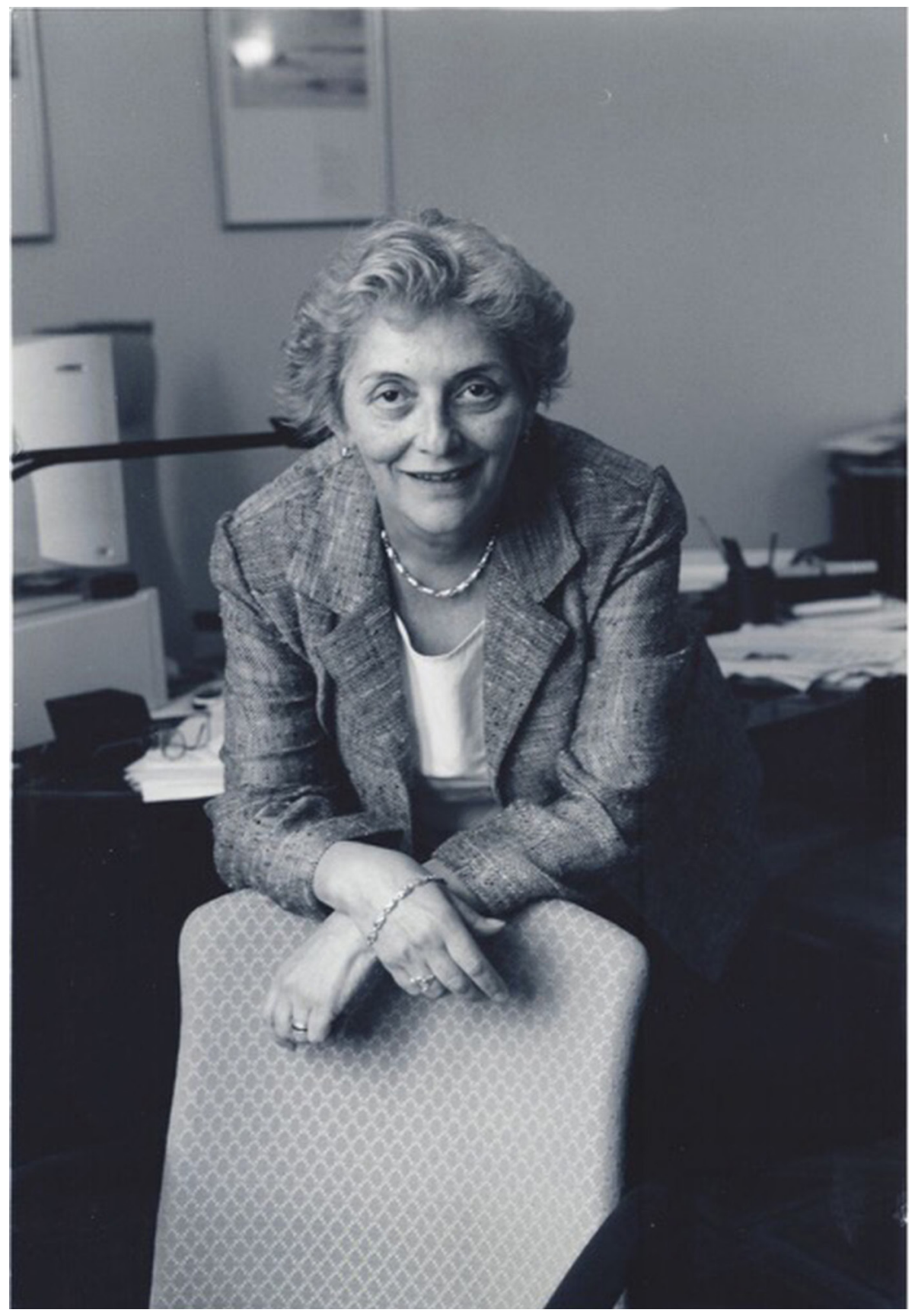


Sagrario López Poza, Nieves Pena Sueiro, Mariano de la Campa, Isabel Pérez Cuenca, Susan Byrne, Almudena Vidorreta (editores)

Docta y sabia Atenea. Studia in honorem Lia Schwartz

N. ${ }^{\circ}$ de páginas: 832

$17 \mathrm{x} 24 \mathrm{~cm}$.

Índice: pp. 7-10

ISBN: 9788497497046

Depósito Legal: C 53-2019

CDU: $821.134 .2(082.2) *$ SCHWARTZ

IBIC: DS | 2ADS | DQ

Editan:

Universidade da Coruña, Servizo de Publicacións

Instituto Universitario "La Corte en Europa" (IULCE), Universidad Autónoma de Madrid

Hispanic Seminary of Medieval Studies (HSMS), New York

Queen Sofía Spanish Institute, New York

Seminario Interdisciplinar para el estudio de la Literatura Áurea Española (SIELAE), Grupo Hispania, Universidade da Coruña

(C) Los autores

(C) De esta edición:

Servizo de Publicacións, Universidade da Coruña

Colección: Homenaxes n. ${ }^{\circ} 14$

Diseño de la cubierta: Paula Lupiáñez (Cirugía Gráfica. Madrid)

Interior: Juan de la Fuente

Impreso en Lugami Artes Gráficas, Betanzos (España)

Printed in Spain 


\section{ÍNDICE}

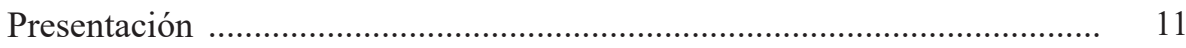

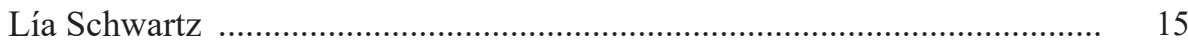

Bibliografía de Lía Schwartz ................................................................. 19

\section{Estudios en homenaje a la profesora Lía Schwartz}

Antonio Azaustre

Notas sobre la filiación en la tradición manuscrita de El alguacil endemoniado

Mercedes Blanco

Para una definición del gongorismo. El caso de Nueva España

69

JAVIER BLASCO

«Salta Pan, Venus baila, Bacho entona»: el campo léxico de la música como vehículo del erotismo en la poesía de los Siglos de Oro

SUSAN BYRNE

La armonía neoplatónica en "A Francisco de Salinas» de fray Luis de León

Mariano de La CAMPa

Poemas de Quevedo en impresos del siglo XVII: Los Romances varios .....

Manuel Ángel Candelas

La poesía española en los manuscritos de la Biblioteca Nazionale di Napoli: noticias y textos

ANTONIO CARREÑo

Lope de Vega: «Rompa ya el silencio el dolor en mí»

Donald CRUickshank

Don Toribio Cuadradillos, «avestruz del amor», and El lindo don Diego (with a note on Quevedo) 
María D'Agostino

Un juego de espejos deformantes. La «representación» del conde de Lemos entre Argensola y Cervantes

TREVOR J. DADSON

«Yo no puedo salir del trabajo de parecer a los portugueses castellano y a los castellanos portugués»: Diego de Silva y Mendoza y la poesía hispanoportuguesa de principios del siglo XVII

Ottavio Di Camillo

Of Roasted Eggs and Other Issues in the Celestina

Aurora EGIDO

Retórica y poética de los afectos en el soneto XIV de Garcilaso 265

Santiago Fernández Mosquera

El vicio de la virtud en Los trabajos de Persiles y Sigismunda 283

Flavia Gherardi \& Pedro Cátedra

El Discorso in difesa della poesia de Gian Ambrogio Biffi en el ámbito de la poética italiana y española

AdRIÁN M. IZqUiERDO

Paráfrasis y experimentación poética en el Anacreón castellano de Quevedo

HILAIRE KALLENDORF

Splitting Hairs or Finding Threads: The Labyrinth as Metaphor for Moral Dilemma in the Comedia

José ENRIQUE LAPLANA

La erudición en el Para todos de Juan Pérez de Montalbán

Begoña LóPEZ Bueno

El Ramillete de las Musas Castellanas (Bibliothèque Mazarine, ms. 4047): un canon literario español en el siglo XVII francés. Primera parte

SAGRARIo LóPez PozA

«Amoris vulnus idem sanat, qui fecit». Notas sobre la fortuna de un topos clásico

ISABEL LOZANO RENIEBLAS

El mal latín del episodio de dos falsos cautivos del Persiles 
Alison Maginn

Rubén Darío's Final Chapter: Archer Milton Huntington and the Hispanic Society

Miguel Martínez

Góngora asiático. Notas sobre poesía filipina inédita del primer Barroco ....

José Martínez MiLlán

Isabel Clara Eugenia, ¿una infanta castellana?

Clayton McCarl

Hacia un modelo para el marcado semántico de los textos marítimos de la época colonial

\section{Juan Montero Delgado}

Un soneto desconocido de Pedro Espinosa a Francisco de Rioja en el ms. Span 56 de la Houghton Library (Universidad de Harvard) 561

Nuria Morgado

Pervivencia del Barroco en la poética de la modernidad: intuiciones y conceptos en el pensamiento literario de Antonio Machado

FRANCISCA MOYA DEL BAÑo

La presencia de Plauto en Quevedo

VALENTINA NIDER

El oro como botín en los poemas de Quevedo sobre Belisario (B-267 e

B-281) y el contexto literario hispano-italiano

ISABEL PÉREZ CUENCA

Francisco de Quevedo y Antonio Sancho Dávila y Toledo Colonna, III marqués de Velada

FERnANDo Plata

El sentido de «barranco» en La Perinola de Quevedo y en otros textos del Siglo de Oro 653

José María Pozuelo Yvancos

Interdiscursividad: cine y literatura en Javier Cercas 671

Augustin Redondo

El tema de la mujer caída de una torre abajo: tradiciones culturales (grecolatinas, bíblicas, folklóricas), creencias religiosas y creaciones cervantinas ... 
MANUEl Rivero RODRÍGUEZ

El conde duque de Olivares, mecenas de la Historia y creador de opinión ... 701

MARIE RoIG Miranda

Los Sueños de Quevedo o cierto tipo de novela 723

Melchora Romanos

Séneca en las Anotaciones de Pedro Díaz de Rivas a los poemas mayores de Góngora

JAVIER SAN JosÉ LeRA

La Política de Dios de Quevedo como comentario bíblico: Política, Biblia y Literatura

LuIs SÁNCHEZ LAÍlLA

Ignacio de Luzán y la musa bucólica

Almudena Vidorreta

Teresa de Jesús, precursora de Gabriela Mistral y Alfonsina Storni

JUAN DiEgo VILA

«con las ansias de la muerte»: El aparato prologal del Persiles como programa estético del estilo tardío cervantino 


\title{
«Salta Pan, Venus baila, Bacho entona»: el campo léxico de la música como vehículo del erotismo en la poesía de los Siglos de Oro ${ }^{1}$
}

\author{
JAVIER BLASCO \\ Universidad de Valladolid
}

Tal música, ella y Pedro compusieron cual nunca será en órganos hallada

Hoy ya no hay nadie que dude que el Siglo de Oro español cuenta con una producción importante de literatura erótica. Los textos representativos de esta escritura, aunque no se les otorgase el honor de la letra impresa (salvo excepciones que hallaron espacio en cancioneros cortesanos, al abrigo de muy variadas temáticas) y tuvieran que correr manuscritos, no son objeto de especial recelo o prevención para quienes se ocupaban de la moral pública, que toleraban y, en algunos casos auspiciaban, la circulación de los mismos por claustros universitarios y conventuales, del mismo modo que toleraban, y en muchos casos bendecían, las pícaras canciones que eran parte esencial del folklore con el que se adornaban bodas o festividades religiosas. Así sucede, al menos hasta el siglo XVIII. Como he estudiado en otro lugar (Blasco: 2015, 2016), en la misma Salamanca de Fray Luis, traductor de Horacio, Melchor de la Serna compatibiliza la traducción del Arte de amor de Ovidio con la enseñanza y la predicación. El

1 Este trabajo forma parte de la investigación realizada en seno del proyecto de Investigación «Ovidio versus Petrarca: nuevos textos de la poesía erótica española del Siglo de Oro (plataforma y edición)» (Ref. FFI2015-68229-P), que se realiza en la Universidad de Valladolid dentro del Plan Nacional de I+D+i (MINECO FEDER). 
hecho de ser uno de los predicadores con mayor audiencia no le impide dedicar sus ocios a los juegos de ingenio erótico que conforman el Jardín de Venus. Y estos ocios (datados a principios de los años ochenta del siglo XVI) se difunden libre y profusamente entre los escolares, como bien muestra Girolamo de Sommaia en su Diario. La cantidad de copias que han llegado de muchos de los textos más representativos de esta literatura muestra que ni la Inquisición ni la censura se esforzaron especialmente para acallarla (quizás, porque no se la tomaron muy en serio) y que la transmisión manuscrita cumplió su papel. Copias de los poemas más desvergonzados de Melchor de la Serna, a tenor de los manuscritos que se han conservado, circulan a partir de 1585 (además de por Salamanca) por los estudios de Valladolid, de Zaragoza, de Florencia, de Roma, y de muchos otros lugares (Blasco: 2016, 16-17).

Sin embargo, si es cierto que en su tiempo esta literatura se toleró sin gran escándalo (posiblemente porque, al circular sólo o principalmente entre gentes de letras, no se consideró peligrosa), los círculos eruditos que, a partir del siglo XVIII y casi hasta nuestros días, empezaron a construir la historia literaria de los siglos precedentes siempre actuaron, en relación con los textos de contenido erótico, con cierta cursilería pacata (Schatzmann Willvonseder, 2003; Díez Fernández, 2003) y eso ha influido en el hecho de que hoy no contemos aún con un glosario suficiente de voces explícita o implícitamente especializadas en el tratamiento de lo erótico.

En referencia a un futuro «diccionario histórico de términos sexuales coyunturales y estructurales» que tuviere como centro la poesía de nuestro Siglo de Oro, Gaspar Garrote Bernal (2012) señala como fuentes básicas para el mismo el «Vocabulario» de Alzieu, Jammes y Lissorgues (Poesía erótica del Siglo de Oro, 1984: 329-354), el «Ensayo de un vocabulario erótico de los entremeses del Siglo de Oro» de Huerta Calvo (1983: 39-68), el «Glosario de términos equívocos» de Vasvari (1983: 317-324) y el «Apéndice II. Vocabulario» de McGrady (1984: 105-108). Y a estas fuentes podría añadirse el «Glosario» con que Jack Weiner (1975) acompaña su edición del Cancionero de Sebastián de Horozco; el glosario de la antología de Herrero, Martínez Deyros y Sánchez Mateos (2018), y varias referencias más sobre la lengua del erotismo, aunque estas se limiten ahora al estudio de campos semánticos o léxicos específicos: nombres de animales (P. J. Chamizo Domínguez y M. Zawislawska, 2006), el término «foder» en gallego medieval (Montero Cartelle: 2004), el lenguaje de las paremias misóginas (Martínez Garrido, 2005). Además, quien se interese 


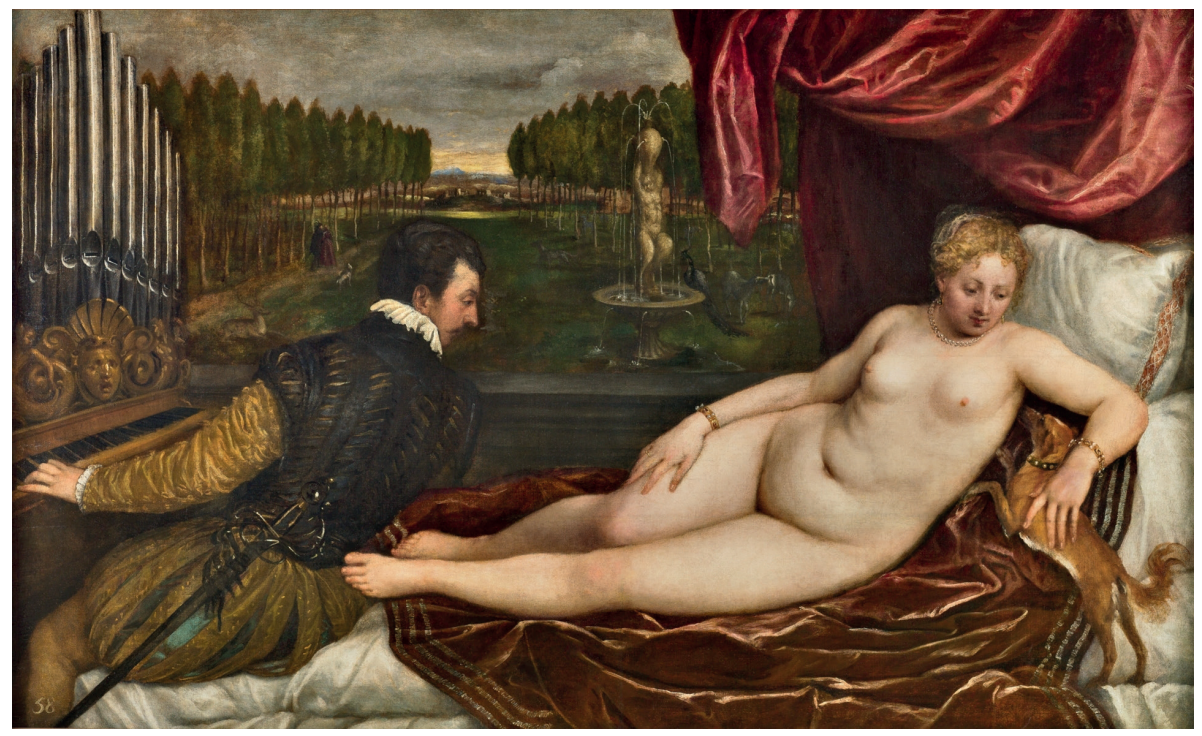

Tiziano, Vecellio di Gregorio (ca. 1490 - 1576)

Venus recreándose en la Música. Museo del Prado (Madrid).

por la presencia de la literatura de los siglos XV, XVI y XVII en este futuro diccionario deberá tener muy en cuenta obras más generalistas como los estudios de José Luis Alonso (1976, 1979), Criado de Val (1981) o Reynal (1988) sobre ciertas formas marginales y, desde luego, fundamentales resultan también la ediciones críticas anotadas de obras del periodo que nos ocupa.

Respecto al corpus de referencia a partir del cual construir el mencionado diccionario, contamos también con un punto de partida relevante. El proyecto Erosylogos [erosylogos.com] ha elevado a 750 poemas (más variantes $)^{2}$ el corpus (144 poemas, más variantes) con el que trabajaron Alzieu, Jammes y Lissorgues, lo que debería traducirse en un notable incremento del vocabulario erótico registrado en Poesía erótica del Siglo de Oro. Ello permitirá documentar cómo el erotismo invade, y contamina, el léxico de la zoología y la horticultura, de la caza, de la guerra, de la

2 Tanto de manuscritos directamente trabajados por nosotros como de ediciones sobre la base bibliográfica de Antonio Rodríguez Moñino (1959, 1968), los trabajos de Brian Dutton (1990), y la labor editorial continuada y fecunda del equipo de José J. Labrador, Ralph A. Di Franco y sus colaboradores. 
música, del juego, de la topografía y la arquitectura, de los distintos oficios, del folklore, del santoral, del refranero y, en general, de la totalidad de la realidad física, social y moral del momento. En la elaboración de ese diccionario, especializado en términos susceptibles de recibir (por el contexto o por trasferencia metafórica) una carga semántica de carácter erótico, estamos trabajando y las páginas que siguen pretenden ser un ejemplo de ello, aunque, por las limitaciones lógicas de espacio, reduciré la muestra al campo semántico de la música, con la mirada puesta a la vez en la juguetona Venus y en la curiosidad del músico (los ojos en la partitura) que ameniza la escena de «Venus recreándose en la Música», de Tiziano.

Unas consideraciones previas se hacen necesarias. En la poesía aurisecular no faltan los ejemplos de expresión directa y cazurra de lo erótico, como no faltan delicadas (o no tan delicadas) manifestaciones populares vinculadas al folklore que no evitan el término propio con el que literal y habitualmente se nombran los referentes eróticos. Sin embargo, lo que predomina, cuando hablamos de un tratamiento naturalista de las relaciones amorosas, es la expresión indirecta y figurada, en donde la metáfora, el eufemismo, el calambur o la dilogía, trabajan en favor de una textualidad que, para el autor, se convierte en espacio excelente para mostrar el ingenio, lo que se traduce, para el lector, en un apasionante reto interpretativo.

Con frecuencia, los estudios lexicográficos que se han ocupado del erotismo aurisecular han tendido a su análisis en el contexto de lo marginal, haciéndole compartir espacio con lo escatológico, lo satírico o lo sencillamente jocoso. Sin embargo no es este el único contexto (ni siquiera es el mejor) para entender el significado de lo erótico en la poesía española de los siglos XVI y XVII. Es cierto que en el corpus que hemos podido reunir en Erosylogos existen muestras de la pervivencia de una tradición cazurra que se remonta, por lo menos, al Arcipreste de Hita y que ocupa espacio notable en los Cancioneros, así como ejemplos de otra tradición de carácter folklórico y popular que se conserva en la memoria popular. Ambas perviven en la poesía de los Siglos de Oro, y desde luego un estudio del erotismo literario no debe ignorarlas. Pero ni una ni otra tradición son verdaderamente representativas de la línea, esencialmente culta, que se inicia 
a partir de las traducciones clásicas [Ovidio especialmente, pero también Catulo, Marial, etc. (Arcaz: 1995, 2005)] y que es la que verdaderamente incorpora elementos caracterizadores que no estaban en las heredadas de los siglos anteriores; a saber: predominio de una intencionalidad lúdica que, muy lejos de los valores que actualmente se le suponen a lo erótico, tiene que ver con una voluntad de exhibición de ingenio; enfoque naturalista de las relaciones amorosas con clara voluntad de distanciamiento de las doctrinas neoplatónicas que dominan en la tradición petrarquista; léxico que remite a campos semánticos muy específicos y de cierta especialización culturalista; gusto por la intertextualidad (en la mayor parte de los casos, con voluntad paródica); y, finalmente, búsqueda de la complicidad con el lector en una clara reivindicación, sobre cualquier otra, del placer textual.

No tengo ahora espacio para desarrollar cada una de estas características. A alguna de ellas me he referido ya en el pasado (por ejemplo, el naturalismo de inspiración aristotélica, Blasco: 2017), y de otras me ocupo en trabajos que se hallan en curso. Ahora me limitaré a hacer algunas reflexiones sobre la fertilidad en esta poesía de un léxico procedente de campos semánticos relacionados con la música.

El autor del Siglo de Oro tiene la necesidad, trate de lo que trate su escritura, de mostrarse como hombre agudo e ingenioso. $\mathrm{Y}$ tal necesidad va en aumento a partir de la segunda mitad del siglo XVI. El «escribo como hablo» valdesiano va perdiendo vigencia conforme avanza el siglo hasta ser plenamente reemplazado, ya en el XVII, por otro lema: «E' del poeta il fin la meraviglia, ¡chi non sa far stupir vada alla striglia!». Giovani Battista Marino, su autor, coincidía en muchos puntos (antipetrarquismo y gusto por lo erótico) con el cambio de paradigma poético que conoce España en el último cuarto del siglo XVII y su influencia en Francia (escuela de los «libertins»), en España (Lope) e Inglaterra (Milton) fue notable.

Gracián, sobre todo, con su Agudeza y arte de ingenio elevará a norma estética, pero también moral y política, la tesis del italiano. Relacionado el ingenio con la inuentio tanto como con la elocutio, Gracián valorará como obra propia de «ángeles» la agudeza y los juegos verbales y de ingenio. Pero antes de Gracián, la poesía erótica, en la que el sentido lúdico de la vida y de la escritura resulta fundamental, había iniciado el camino en esta misma dirección, sintiéndose quizás heredera (por encima del petrarquismo imperante) de la lírica de cancionero. El hecho cierto es que el tratamiento de lo erótico enseguida vendrá a reclamar del lector, como 
quería Gracián, la acreditación de «águila» por la complicidad que se le exige para descifrar sus agudezas.

El hecho es que para el poeta barroco hay materias (pensaban muchos con Baltasar Gracián) sobre las que sólo es prudente hablar por medio de alusiones, de modo que la lectura demandará que el receptor supla con buen entendimiento lo expresado indirectamente (mediante la metáfora, el eufemismo, la perífrasis, la dilogía, el calambur, la paronomasia, la polisemia, el equívoco, etc.) o lo simplemente insinuado por el contexto. La de erotismo era una de esas materias que, casi por definición, exigía la elusión del nombre propio de las cosas. $\mathrm{O}$, dicho de otro modo, la materia erótica reclamaba la expresión aguda para mantener el picante del juego y, además, evitar lo burdo y torpe de la literalidad. Así, Trillo y Figueroa necesita vestir de adivinanza el «acá vengo vecina, / a meter lo mío en lo vuestro; / si me lo dieses, lo haremos presto», porque la expresión directa de lo erótico se considera no tanto pecaminosa cuanto grosera (por falta de recursos para ser aguda). Las connotaciones que rodean al erotismo (relacionadas más con lo que ocurre «de puertas adentro» en el territorio de lo íntimo que con lo pecaminoso o prohibido) convierten sus materiales en privilegiado escenario para una exhibición de agudeza por parte del autor, destinada a «maravillar» a sus lectores con ingeniosos modos de «alumbrar a dos luces» unos temas y unas escenas, en los que, para evitar la expresión burda o soez, había que recurrir al lenguaje figurado. Si la poesía erótica recurre a una forma indirecta de hablar no es ni por un ejercicio de prudencia moral o religiosa, ni por evitar la censura. Cerezo sostiene, y creo que a falta de estudios específicos al respecto hay que darle la razón, que «no hubo en España esa preocupación por el "control bibliográfico" [...] como sucedió en otros países de nuestro entorno, cuyos primeros repertorios comienzan a aparecer a partir de la segunda mitad del siglo XIX» (2001, p. 13).

Lo que domina en la expresión de lo erótico es la voluntad de mostrar ingenio y de disfrutar del ejercicio lúdico de una escritura que será tanto más perfecta cuanto mejor conserve la posibilidad de mantener a lo largo de todo el texto los dobles sentidos, el literal y el metafórico. Al esfuerzo del autor por conseguir un discurso polisémico, deberá responder un lector cómplice, dispuesto a aplaudir el ingenio con que se enmascara la lectura maliciosa bajo la literalidad del poema. Este lector deberá poseer mirada de «águila», esto es, un alto nivel de competencia y de agudeza; y habrá de compartir con el autor, en grado suficiente, el conocimiento de aquellos 
referentes que alimentan el léxico (vehículo) con que figuradamente se expresa aquello de lo que, sin nombrarlo, realmente se habla (tenor) ${ }^{3}$.

Los escritores de los Siglos de Oro dedicaron no pocos esfuerzos a componer textos de alta carga erótica, que en la mayor parte de las ocasiones eran desenfadados ejercicios retóricos para pulir el estilo o formaban parte de un juego (apreciado en los círculos universitarios y no condenado en el interior de los conventos), en el que por lo general el ingenio ocupaba un lugar importante. Este divertimento (esencialmente culto, aunque en muchas ocasiones recurriese a un léxico cazurro) dio origen a muchos textos que circularon en forma manuscrita y que sólo en raras ocasiones alcanzaron el honor de la letra impresa (una relevante excepción lo constituye el Cancionero de obras de burlas, 1519). El gusto por lo erótico no sólo estaba discretamente aceptado, sino que gozaba de cierto prestigio intelectual. Contaba con modelos dignos de imitación en la antigüedad clásica (Anacreonte, Plauto, Marcial, Propercio, Catulo, Ovidio, y tantos otros) y con notables antecedentes en la literatura goliardesca que, por ejemplo, alcanzaba cotas relevantes en el Carmina burana e impregnaba la literatura cortesana de los primeros cancioneros. Circulan libremente por los estudios universitarios y por las celdas de los conventos (masculinos y femeninos) y son antes motivo de entretenimiento (incluso compatible con la doctrina de la eutrapelia) que piedra de escándalo. No buscan tanto provocar cuanto exhibir agudeza. Desde luego, estaba muy lejos esta literatura de constituir una actividad clandestina, $y$, aunque la transmisión manuscrita reduce la posibilidad de difusión de un texto, a la vista de cantidad de testimonios por la que han llegado a nosotros muchos de los poemas de contenido erótico, se puede afirmar que en su tiempo alcanzaron masas no pequeñas de lectores. Pero sí es cierto que, a partir de un momento (en torno a 1550) chocan con el prestigio de unas doctrinas amorosas (Ficino, León Hebreo) que limita retóricamente las partes de cuerpo que cuentan con «prestigio literario» (y, en consecuencia, social); unas doctrinas amorosas que reducen el amor a un proceso síquico, negando todo lo que en dicho proceso tiene que ver con el instinto. Espíritus contra hormonas o, como rezaba un romance del Conde de Rebolledo, amor (al que muchos

3 Los términos tenor y vehículo deben leerse con el sentido que les otorga Stephen Ullman: «Siempre hay presentes dos términos: la cosa de la que estamos hablando y aquella con quien la comparamos [... ] el primero es el tenor (tenor); el segundo, el vehículo (vehicle); mientras que el rasgo o los rasgos que tienen en común constituyen su fundamento (ground)» (1972: 240). 
«adoran por dios»] contra apetito (al que algunos «culpan por vicio»]. Contra tal reducción, un aristotelismo de fondo, que va imponiéndose al neoplatonismo en la última década del XVI (Varo Zafra: 2007, 103 y ss.), reivindica territorios en la expresión de lo erótico que le estaban vedados al petrarquismo (Blasco: 2017). Bien lo expresa el «Quiero gozar, Gutiérrez; que no quiero / tener gusto mental tarde y mañana», de Quevedo.

Lo que ocurre con la música, como campo semántico que proporciona gran cantidad de voces para la expresión de contenidos picantes, podría confirmar que esta poesía es, antes que cualquier otra cosa, fruto del puro ejercicio retórico, o mero juego literario para lectores cómplices que comparten con el lector la clave precisa (ciertamente culturalista) para descodificar lo que el texto silencia o expresa indirectamente. De alguna manera el autor se dirige a sus propios compañeros de claustro o de estudio, lo que justifica todas las agudezas con las que va sembrando el texto y la exigencia de complicidad en la gestión de las mismas. Alberto Blecua escribió respecto a los problemas de interpretación que plantea la literatura barroca: «Las obras maestras suelen deleitar a los lectores y martirizar a los críticos que intentan aprehender desde su perspectiva histórica e ideológica la pluralidad de sentidos que, al parecer, yacen ocultos tras la corteza de la literalidad» (Blecua: 2010, XIII). Esto vale también —y de manera muy especial - para la poesía erótica, porque en ésta la complicidad con el lector es consustancial a su textualidad. Muchos sentidos se nos escapan y no son pocos los textos que, quizás por temor a la sobre-interpretación, se siguen resistiendo a la lectura que potencialmente «yace tras la corteza de la literalidad». Hay un texto, recuperado por Labrador (Cancionero de poesías varias: 1989, n. 173) que me parece paradigmático:

\author{
Dulces labios hermosos, \\ que mil veces estáis mil besos dando, \\ y a mi alma alegrando, \\ con un sonido manso, \\ juntamente matáis y dais descanso. \\ Porque si me besáis, \\ en besos me lleváis envuelta el alma, \\ y si muriendo ceso, \\ mil vidas me volvéis con sólo un beso. \\ Y pues que a puros besos me habéis muerto, \\ resucitadme, joh labios amorosos, \\ más dulces que la miel y más sabrosos!
}


La lectura literal de estos versos nos obliga a situarlos en el marco del petrarquismo. Pero si aplicamos a los mismos la lectura metafórica de muerte (deturgere) y resurrección (iterum arrigere) que se impone en multitud de contextos eróticos, el yacente significado se levanta e impone sobre el literal. La letra, diría Rojas, «se despereza» enarbolando un significado que va más allá de lo denotado por los términos.

Uno de los retos críticos que esta literatura sigue planteando tiene que ver con la necesidad de despertar (sin caer en la sobre-interpretación ${ }^{4}$ ) los sentidos silenciados tras el velo de los signos, que siglos de moralina pacata han pretendido enterrar ${ }^{5}$. Y hay que apostar en esta dirección porque, como señala Donald McGrady (1984, 93-94), la riqueza metafórica de un erotismo velado tras un léxico indirecto deja entender más profundamente la lengua y pensamiento de nuestro Siglo de Oro. Y en esta línea se hace preciso seguir reivindicando el profundo sentido vitalista y lúdico de dicho pensamiento. Bastarán unos pocos ejemplos (que tienen la música como eje común) para mostrar que, a pesar de la materia tratada, el placer textual se erige como objetivo casi único de la escritura erótica.

La polisemia del léxico con el que se construye un texto en bastantes casos depende de la elección de un término lexicalizado, esto es, un término al que con el tiempo, sin perder su primera acepción, el uso ha enriquecido con un sentido figurado del que ya no podrá desprenderse (es el caso de voces como instrumento, órgano). Pero en la mayoría de los casos es el contexto el que ocasionalmente «resemantiza» las palabras que

4 Algunas reglas para asegurar la interpretación correcta buscan los trabajos de Gaspar Garrote Bernal: «la dificultad para entender hoy el mensaje superficial (o no obsceno) de textos dilógicos del Siglo de Oro, proviene de que en la formulación de la dilogía dominó la intención erótica, de modo que la oscuridad del significado superficial ['A'] no sólo es indicio de falta de ingenio por parte de sus emisores, sino que funcionará como grupo de control textual que predice la segura presencia subyacente de un sentido erótico ['B']» (Garrote Bernal: 2008, 221).

5 En España, tradicionalmente el pecado verdaderamente grueso fue siempre contra el sexto (pecado contra las leyes eternas); los pecados contra el quinto o contra el séptimo se relegan en la tradición católica a una segunda categoría (pecado contra las leyes de los hombres) (Dens: 1777, 7). Eran más fáciles de perdonar. Pero al menos contamos con una nutrida literatura (Erosylogos, quiere ser una muestra de ello) que prueba que no siempre fue así. Esta literatura da ejemplos suficientes de vivencia positiva de lo erótico por buena parte de nuestros escritores de los Siglos de Oro. Otra cosa es lo que vino luego. El hecho mismo de que, como muestra el Códice 22.028 de la Biblioteca Nacional de Madrid, en los siglos XVIII y XIX se arrancaran páginas y emborronaran poemas enteros habla de cómo el decir indirecto de los textos no siempre los preservó de la intransigencia. 
componen el texto favoreciendo las isotopías eróticas. Así, el verbo cantar significa «producir con la voz sonidos melodiosos, formando palabras o sin formarlas» (DRAE), pero el vocablo se «resemantiza» en el contexto de la poesía erótica (futuere); $\mathrm{y}$, como se observará en el poema que sigue, sin invalidad ni agotar la lectura literal, incorpora un nuevo significado que contaminará otras voces del texto, como dormir (deturgere), velado, se entró, armado, postigo (cunnus) y otras. Incluso Arias Gonzalo deja de ser el personaje legendario del romancero, para pasar a ser el arrojado guerrero (penis) de la batalla de plumas que «a desora» se está librando:

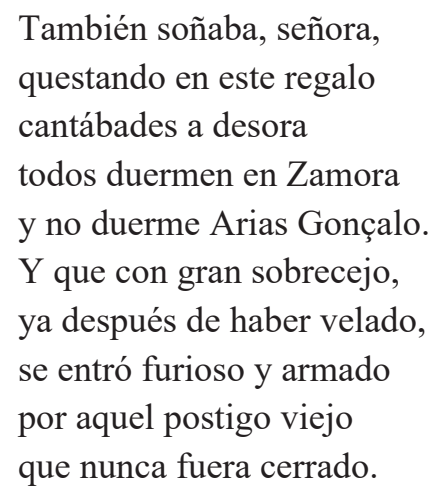

Y no creo que pueda tachárseme de sobreinterpretar el texto. Pertenecen estos versos a un interesantísimo romance que ha llegado a nosotros manuscrito ${ }^{6}$ y que implica un muy curioso juego de intertextualidades a otros varios poemas de romancero viejo. Pero ahora lo que me interesa destacar es la necesidad de un lector cómplice para que la «resemantización» que persigue el autor se logre en la lectura. En muchos casos es el contexto el que favorece el desvelamiento. Así ocurre con el romance en que se insertan los versos anteriores, precedidos por estos otros:

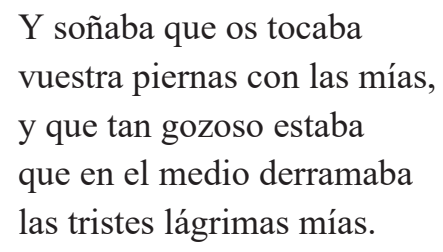

6 «Soñaba, señora mía», en Biblioteca Real de Madrid, manuscrito 2803. 
Esas lágrimas que se derraman, fruto del gozo, no admiten otra lectura que la erótica y en este contexto, erótico, se inscribe el canto de la señora que hemos comentado más arriba.

Lo apuntado hasta aquí permite conjeturar que la lexicalización o «resemantización» a que acabo de referirme es el resultado de unos usos circunscritos en una cultura. De modo que, cuando la enciclopedia sobre la que se construye dicha cultura cambia, la lectura se complica. Por eso es tan importante disponer del mejor vocabulario posible, que nos permita activar las claves de lectura para acceder a los sentidos que, por seguir con lo dicho por Blecua, «yacen ocultos bajo la literalidad». Creo que este vocabulario (en el que estamos trabajando) nos permitirá entender un poco mejor la clase de público al que los textos representativos de la poesía erótica aurisecular se dirigen.

A partir del corpus reunido en Erosylogos, es posible elaborar un vocabulario que complete los existentes. Como muestra de ello, van a continuación las voces que, pertenecientes al campo semántico de la música (quizás uno de los peor representados en los repertorios léxicos dedicados al tema del erotismo en la poesía de los siglos XVI Y XVII), hemos podido registrar. Me limitaré, por espacio, a recoger todas las voces del campo semántico de la música para las que he podido registrar variaciones semánticas en contextos eróticos. Respecto a los ejemplos que cito, espero sean suficientes para observar el proceso de «resemantización» a que me vengo refiriendo. Por supuesto, las voces registradas siguen manteniendo su valor literal, pero una vez contaminadas se convierten en una especie de jerga para lectores cómplices con conocimiento de la claves de desciframiento ${ }^{7}$ :

\section{EJECUCIÓN MUSICAL: VERBOS Y SUS DERIVADOS}

Acento (concumbere, futuere), cantador (futuens), cantante (futuens), cantar (futuere), cante (coitum), concierto (fututio), dar entrada (coitum

7 Todas las voces de este vocabulario se documentan en el corpus reunido en Erosylogos [http://www.erosylogos.com]. El lector puede usar el buscador de la herramienta para seguir cada palabra en los textos que conforman el mencionado corpus. Cito los textos por el «[primer verso]» que es el que nos sirve en Erosylogos para organizar los poemas y por el primer verso también pueden buscarse en la herramienta. 
incipere), dar la salida (coitum finire), entonar ${ }^{8}$ (arrigere, futuere), letra (penis), música (cantus fututionis), organista (futuens), son (futuere), sonar (cantus fututionis), tañer (futuere), templar (arrigere), tocar (tangere, futuere), tono (cf. entonar), toque (tactus, fututio).

Con estas claves, nadie dudará a qué se refiere la dama cuando le pide al galán que «cante por natura» [«Perejil y culantro seco»]. En el mismo sentido, no quedará duda sobre qué es lo que la muchacha hace cuando le «canta el re mi fa sol» al caracol (penis), para que este no se duerma (Dormidito estás, caracol), o a qué se refiere la madre cuando le enseña a la hija que «por bien cantar, / más han de ser estimadas / dos lágrimas bien lloradas (semen)» que todo el «gorjear» del capón [«Di, hija, ¿por qué te matas»]; sabemos qué es lo que Jorgico le promete a su señora cuando le informa de que «soy tal cantador, / que cuando pierdo el tenor / lo cobro con mi garganta. [«Canta, Jorgico, canta»]; entendemos qué «cantaba» esa letra que a Marica «le entró tan bien» y «que hizo pasos de garganta / antes de romper (Devirginare) la nema (membrana uirginalis)» [«A nueve meses de achaque»].

\section{INSTRUMENTOS MUSICALES O PARTES QUE LOS COMPONEN}

Arpa (cunnus), atabales (nates), bandurria, campana (cunnus), cascabeles (testes), clarín, clavija (testes), corneta, cuerda (penis), dulzaina, facistol (mentula), flauta (penis), fuelle (testes), guitarra, instrumento (penis), laúd, lira (penis), llave (penis) ${ }^{9}$, órgano (penis cunnus), pandero (cunnus), pífano, pito (penis), plectro, prima, primera, púa (penis), puente (os pubis), puntero (penis, mentula), rabel (culus), tambor (testes), tamboril (culus) teclas (papilla), tercera, trompa, trompeta, vihuela, viola, zambomba (Priapus), zampoña.

Una seguidilla que nos ha llegado por vía del Jardí de Ramelleres (ms. 9 Biblioteca Ateneo Barcelona) nos ayuda a resolver el significado que debemos dar, junto a lanza y escudo, a tambores y trompetas: «El carajo es la lanza, / el coño, escudo, / los cojones, tambores, / trompeta el culo» [«El carajo es la lanza»]. Sin embargo, no es lo común, como se va viendo,

8 ENTONAR. «Vale también cantar bien y ajustadamente, poniendo el punto en su lugar con todo primor y acierto: y así del que afina bien y se ajusta al instrumento músico se dice que entona bien» $(D A u t)$.

9 LLAVE . «Se llama también el templador de algunos instrumentos músicos: como el harpa» (DAut). 
semejante transparencia. En cualquier caso, casi todos los instrumentos musicales que se registran en nuestro corpus (clarín, órgano, rabel, atabales, etc.) admiten una fácil interpretación en cuanto metáforas de los órganos sexuales de cambiante signo, masculino o femenino, según los textos. Por lo general, flauta, trompeta, trompa, dulzaina hacen referencia al pene, en tanto que tambores, y atabales, en el contexto erótico que estamos analizando, aparecen siempre en boca de un hombre y se refieren a la anatomía femenina. En los siguientes versos se ofrece un consejo masculino, que nos ayuda a identificar el sentido de «atabales»: «Si a la flaca el instrumento / tocáis en sus atabales, / salís con más cardenales / que del potro del tormento» [«Para descansar un rato»]. Por lo general, los instrumentos de viento suelen ser de signo masculino y los de percusión, de signo femenino, pero en muchas ocasiones - merece la pena que lo reseñemos- el poeta elige unos «instrumentos» u otros en función del sonido (más grave o agudo) que producen. Veamos un ejemplo [«Para descansar un rato»], relevante por la riqueza de la isotopía musical, de cómo es la frecuencia de los sonidos (baja o alta) la que orienta al sujeto de la enunciación en su identificación del instrumento que produce la música (cantus):

La música, por lo menos, vino a ser tan resonante, que desde lejos se oían los golpes de los compases. Arpa no fue el instrumento, porque mal pudo templarse, cuando tiene estropeada allá en Navarra la llave. Órgano menos, pues dicen, que no hay flauta que tocase; $\mathrm{y}$, aunque fuelles pude haber, no son fuelles de buen aire. Rabel sería, sin duda, que en la armonía que hace, aunque los tiples resuenen, más los bajos sobresalen. Si ya no es que en el estruendo con que llegaba a escucharse nos dé a entender que serían no clarines, sí atabales. 
Respecto a los elementos que componen los instrumentos musicales o que van vinculados a ellos (cuerdas - prima $^{10}$, tercera- teclas, clavijas $^{11}$ fuelles $^{12}$, facistol, puntero $^{13}$, puente $^{14}$, púa $^{15}$ ), además de añadir a la expresión matices que enriquecen el sentido, demuestran que el autor de los textos no toca de oído, sino que está familiarizado con una cultura que, sin ignorar lo popular, supone unos conocimientos bastante especializados.

\section{Notación, TIPOS DE VOCES Y CLAVES MUSICALES}

Bemol (Languidus, mollis), fuga ${ }^{16}$ (fututio) re mi fa sol (fututio), compás (arrigere-discere), solfa ${ }^{17}$ (fututio), natura (tentus), bajo (rigidus), tenor (tentus), contrabajo (tentus), tiple (mollis), punto $^{18}$ (statum).

10 PRIMA. «En algunos instrumentos de cuerda se llama la que es primera en orden, y la más delgada de todas, que forma un sonido mui agudo» (DAut.). Evidentemente, el autor de los versos que siguen conoce bien el sonido y el grosor de la cuerda prima: «Prima mía, pero miento, / en sentir de los que tocan, / porque tú para ser prima / me pareces algo gorda. / Pero ya que has de ser prima, / lo serás por lo sonora, / porque más que una guitarra / me hablas claro en mi deshonra» [«Mucho deben los hombres»].

11 Véase, más abajo, la expresión «apretar las clavijas».

12 Véase, más abajo, la expresión «alzar los fuelles».

13 PUNTERO. «Se llama también un género de punzón para señalar, de cualquier modo que sea. En las Iglesias y Coros, es una varita larga de metal, con que señalan lo que se ha de cantar o leer» $(D A u t)$. En varios textos vale por penis, mentula [«Cabras hay en el mal lugar», «Si siendo Tomico»].

14 PUENTE. «En la guitarra y otros instrumentos, es un maderito, que se pone en lo más inferior de ella, todo taladrado de agujeritos, en donde se prenden y aseguran las cuerdas por un cabo: y por el otro se ponen en las clavijas: y en algunos, como el violón, es un arquito que se pone para levantar las cuerdas» (DAut.). Léase la siguiente definición a la luz del significado de clavijas y con ayuda de los siguientes versos: «la música entabló al punto / y las clavijas le aprieta; / con lo cual, saltó Marica / como si guitarra fuera. / Toda la puente rompida / y, de abajo arriba, abierta» [«A nueve meses de achaque»].

15 PÚA. «La cosa aguda y delgada que acaba en punta. Díjose porque punza» (DAut.) Una muestra del sentido que este término adquiere en el contexto de la poesía que nos interesa se evidencia en el romance «Los médicos han de errar», donde de un «marido por señas», de los que «sólo amagan y no apuntan», se dice que es «muy hipócrita de púa».

16 FUGA. «En la Música es un concierto dispuesto con tal artificio, que después de cierto tiempo harmónico, cantan las otras voces por su orden lo mismo que cantó antes una, observando los mismos movimientos, intervalos y pausas que ella» (DAut.).

17 SOLFA. «Metafóricamente vale la concordancia, y conformidad de acciones entre personas de diversa clase, ò autoridad» (DAut.).

18 PUNTO. «En los instrumentos músicos es el tono determinado de consonancia, para que estén acordes» (DAut.). 
De nuevo, los términos aquí recogidos nos remiten a una cultura musical nada común en los autores de ciertos textos que encontramos en nuestro corpus (Rubio: 1959). Quizás la distinción entre los tres géneros de canto que establece Domingo Marcos Durán (1498) nos ayude a entender varios de los términos que recogemos en este apartado y su aplicación al «rendimiento» de los «instrumentos»: «El sonido recio es atribuido al género enarmonio, el moderado a natura, el blando al bemol» ${ }^{19}$. Con esta información resulta más fácil entender que la muchacha del poema se queje de que «de un punto muy entonado y sostenido», el «instrumento» del varón haya bajado a clave de «fa bemolado» en estos versos: «caracol, te me has caído (deturgere). / Dabas en mi sostenido / y ya das en fa bemolado. / Pues la clave te he mostrado / canta con más compostura. / Si la clave es de natura, / ¿para qué es tanto bemol?» [«Dormidito estás, caracol»].

Respecto al «sonido» más o menos grave de las voces (bajo, tenor, tiple), valga lo dicho en el apartado anterior para los instrumentos más o menos agudos. De bajo es «la voz o instrumento que en la Música lleva este punto, que es una octava más baja que el tenor» (DAut). Bajo y tenor son las dos voces que se conciertan para producir «dulce armonía» (véase más abajo dulce armonía). Los versos de Quevedo («Yo llevo, marido, el bajo, / y el ciego lleva el tenor, / y está puesto el facistor / en la cámara de abajo») se entienden correctamente a la luz de la respuesta que da Pinciano a Palatino cuando éste le comunica que nunca le gustó la música de monjas: "Alguna razón tenéis porque, como todas son tiples y unísones, no pueden hacer perfecta música por diestras cantoras que sean, aunque algunas hay que cantan tenores y contrabajos» (Arce Otalora: 1995, II, 804). En cualquier caso, en varios de los textos de nuestro corpus bajo y natura funcionan como dilogías apuntando en un mismo enunciado a la anatomía y a la música. [«Cabras hay en el mal lugar», «Mucho deben los hombres», «Para descansar un rato»] [«Atended por cortesía»] [«Dormidito estás, caracol»], [«A un sacristán su mujer»].

19 «Estos III géneros [de canto] son atribuidos a estos tres de que vsan los eclesiásticos, scilicet, bequadrado, natura y bemol. El bequadrado es atribuido al enarmonio, natura al dyatónico, bemol al chromático. Assí mesmo, son comparados a estos tres géneros de sonido, scilicet rezio, moderado y blando. El sonido rezio es atribuido al género enarmonio, el moderado a natura, el blando al bemol» (Marcos Durán: 1498). 


\section{EXPRESIONES}

Alzar los fuelles: El fuelle (Testes) es un «instrumento conocido para recoger viento y volverle a dar, del cual se sirven ordinariamente los Herreros y otros Artífices para avivar el fuego de la fragua, y los tiene el órgano para dar viento al secreto, y de allí a los caños» (DAut). En música el fuelle da aire para que, a través del secreto, alimente los caños del órgano en función de las teclas que mueve el organista. Ya Sebastián de Horozco escribía sobre «compañones como fuelles arrugados». Sobre esta comparación se produce la «resemantización» que observamos en los textos analizados que recurren a este término. Los términos fuelles, secreto y caños constituyen (junto a tirantes, árbol, tubos, y teclas) diversas partes del órgano barroco español, y todos ellos quedan contaminados por el significado erótico. Ya la pícara, en La pícara Justina, presumía de que «Si Justina no entonara los fuelles, maldita la tecla había que sonara bien». Merece la pena que citemos ahora algunos versos más representativos: «Y organistas del amor / fueron luego de manera, / que ella le alzaba los fuelles / y él le tocaba las teclas. / Parecióle bien la solfa, / y a juntar Marica empieza / un instrumento con otro / con que, luego, fue maestra». [«Para descansar un rato», «A nueve meses de achaque», «Mal viejo desvariado», «Las nueve que habitáis en el Parnaso»].

Apretar/templar las Clavijas: Testes, penis. Apretar las clavijas es fundamental para templar el instrumento. Según del Diccionario de autoridades, la clavija es «Clavo pequeño hecho de madera o de hierro, en el cual se prenden y revuelven las cuerdas de los instrumentos músicos, para que estén tirantes, y mediante las cuales clavijas se suben y bajan para templar el instrumento». Ajustar las clavijas (arrigere). «Mas esto de estar la cuerda / a todas horas templada / y tirante la clavija, / solo los frailes lo alcanzan». [«A nueve meses de achaque», «Contra mí corto la pluma»].

Apretar/templar las cuerdas: Penis. Cuerda «se llama también aquel hilo delgado que se hace de tripa de carnero, de alambre o plata, y sirve para poner en los instrumentos músicos: como vigüelas, harpas, cítaras y clavicordios, las cuales heridas, hacen sonar el instrumento». (DAut). La expresión «ajustar / apretar la cuerda» (glubere, concumbere) aparece en contextos eróticos para referirse al paso de ajustar los instrumentos y prepararlos para el canto (futuere) [«A nueve meses de achaque»]. 
Cantar por natura (futuere): natura «en la música es una de las tres propriedades della, en que el hexachordo comienza en la clave de césolfaut, y es la que media entre las propriedades de bequadrado y bemol» (DAut). Pero con el término natura se designa también los atributos sexuales, tanto del hombre [«El mozo era pujante de natura»] como de la mujer («recordó y halló su dedo / metido en la natura de su dama») [«Rabiosos celos le tenían perdido»]. Sobre esta polisemia, se construye la agudeza de los versos que siguen, en los que se duda de la virilidad del «cantante» de Juanilla [«Dicen que tienes, Juanilla»]:

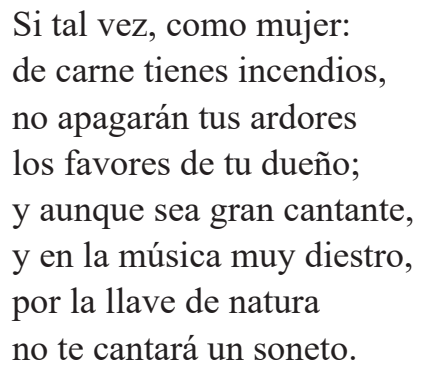

Llevar el compás: «En la Música es el tiempo que hay en bajar y levantar la mano el Maestro de Capilla, o el que rige el canto. Divídese en Binario y Ternario: el Binario consta de dos partes iguales, una al dar, y otra al alzar: el Ternario de tres, una al dar, y dos al alzar» (DAut.) Como se deduce de la definición anterior, el término tiene que ver tanto con el sonido como con el movimiento que el maestro de canto va haciendo con el puntero. El compás marca el ritmo y esta es la base de identidad que permite la «resemantización» erótica del término [«A un sacristán su mujer»]:
Gusto era cómo entonaban
dama y galán por lo bajo
Un parce-mihi, cuando él
un tuum-da-nobis por alto.
Tiple la mujer hacía,
él escolar contrabajo,
y el sacristán el compás
les llevaba con la mano.

Canto llano: con este nombre se designa a la música vocal (de origen monacal), con una única línea melódica. Generalmente no lleva acompa- 
ñamiento de instrumento musical alguno salvo el conseguido por la propia voz. Al «canto llano» recurre Justina cuando un ermitaño se empeña en consolarla: «Él, entonces... aun asomó a quererme consolar por la mano, por consolarme en arte de canto llano, que comienza por la mano. Mas yo, como intentaba consuelos en contrapunto, ahorréle esta diligencia» (López de Úbeda: 1977, II, 435). Estas agudas palabras contienen la clave para la lectura de los versos que siguen [«Cabras hay en el mal lugar»]:

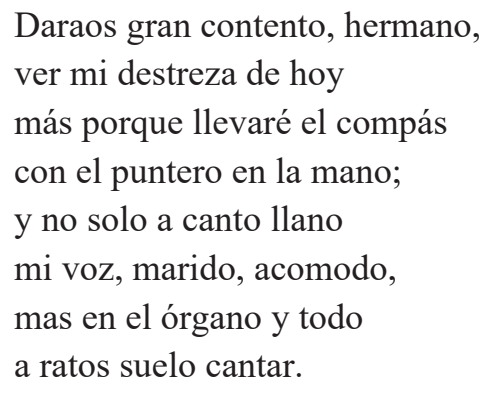

Dulce armonía: Concumbere, futuere. «Significa el eco o consonancia que hacen las cosas que se vén o oyen...» (DAut). En la «resemantización» erótica, se toma el todo por la parte, «lo que se oye» por «las acciones que producen el sonido». Sobre esta base, se escriben los versos de Trillo y Figueroa: «Llegado pues el concertado día, / o por grande vergüenza o por contento, / no pudo alzar cabeza el instrumento / para forjar los dos dulce armonía». Para que la armonía sea dulce — según Lorenzo Matheuconviene que «los tiples resuenen» y «los bajos sobresalgan». [«Viendo una dama que un galán vivía», «Puesto ya un pie en el estribo», «Para descansar un rato», «La red que con ingenio y sutil arte»].

Pasos de garganta: «Los quiebros de la voz, destreza y facilidad con que alguno canta» $(D A u t)$. Pero estos «quiebros de voz» no son, evidentemente, los que se citan en los versos de Quevedo que recordábamos más arriba, ni tampoco los del romance «A nueve meses de achaque», atribuido a Trillo y Figueroa:

Diole una letra a Marica, y entrole tan bien la letra, que hizo pasos de garganta antes de romper la nema. 


\author{
Y organistas del amor \\ fueron luego de manera, \\ que ella le alzaba los fuelles \\ y él le tocaba las teclas.
}

El erotismo coloniza e invade todos los espacios y actividades cotidianas y se apropia de su léxico contaminándolo (también, el de la música) en discursos que apuntan en dos direcciones. Baltasar Navarrete, en La pícara Justina, lo expresa con una precisión que nos ahorrará cualquier otra explicación: «díjome —el ermitaño del capítulo II, número III - muchas cosas que de suyo provocaran a castidad, si él no castrara la fuerza dellas con ser quien era. Decía sin duda, buenas cosas, pero con un modillo que destruía la substancia de la dotrina, que bien parecía obra de diferentes dueños, pues la sustancia olía a Dios y el modillo a Bercebú» (López de Úbeda, 1977, II, 435). Se crea así un discurso esencialmente metafórico en el que la ausencia del tenor, o término que literalmente nombra aquello de lo que se habla, convierte el texto en un excitante juego que obliga al lector a interpretar si debe otorgar más atención a la «sustancia de Belcebú»o al «modillo de Dios».

Pero la excitación de esta literatura no es la misma que persigue el escritor actual del género. En el erotismo aurisecular, lo lúdico se impone siempre - incluso en la expresión cazurra — sobre lo erótico. Es una forma de introducir en la vida diaria un espacio de juego en el que autor y lector se encuentran en una misma voluntad de rebajar la seriedad de la existencia. En este sentido, muchos de los textos que componen el corpus que hemos podido reunir adoptan la forma del chiste o de la adivinanza; ponen letra a ciertas canciones vinculadas a las celebraciones populares de carácter folklórico; e incluso parodian — sin acritud ni reivindicación algunaformulismos litúrgicos o glosan textos tan serios como el padrenuestro o alguno de los salmos (por ejemplo, el Salmo 136, Super flumina). 


\section{BIBLIOGRAFÍA}

Alonso Hernández, José Luis, Léxico del Marginalismo del Siglo de Oro, Salamanca, Universidad de Salamanca, 1976.

Alonso Hernández, José Luis, El lenguaje de los maleantes españoles de los siglos XVI y XVII: La germanía (Introducción al léxico del marginalismo), Salamanca, Universidad de Salamanca, 1979.

Arcaz Pozo, J. L., «Passer mortus est: Catulo (carm. 3), Ovidio (am. 3, 7) y Maximiano (el. 5, 87-104)», Cuadernos de filología clásica: Estudios latinos, 8 (1995), pp. 79-88.

Arcaz Pozo, J. L., «La poesía latina en el contexto amoroso de la comedia elegíaca medieval: Catulo y Ovidio en el De tribus puellis», Cuadernos de filología clásica: Estudios latinos, 25 (2005), pp. 101-110.

Arce de Otalora, Juan, Coloquios de Palatino y Pinciano, ed. José Luis Ocasar Ariza, Madrid, Turner, 1995.

Beltrán Noguer, M. T. y Á. Sánchez-Lafuente Andrés, «La Sátira Sexta de Juvenal o el tópico de la misoginia», Myrtia, 23 (2008), pp. 225-244.

Blasco, Javier, «En el nombre de Venus: un arte de amar español del siglo XVI», en «Lasciva est nobis pagina»: erotismo y literatura española en los Siglos de Oro, Pontevedra, Editorial Academia del Hispanismo, 2015, pp. 143-179.

Blasco, Javier, «Introducción» a Melchor de la Serna, Arte de amor, Valladolid, Agilice Digital, 2016.

Blasco, Javier, «"¿No es esto animal?”: Ovidio versus Petrarca», en Patricia Marín Cepeda (ed.), "En la concha de Venus amarrado»: erotismo y literatura en el Siglo de Oro, Madrid, Visor, 2017, pp. 13-26.

Blázquez, J. M., «Conductas sexuales y grupos sociales marginados en la poesía de Marcial y Juvenal», en G. Bravo y R. González Salinero (eds.), Minorías y sectas en el mundo romano. Actas del III Coloquio de la Asociación Interdisciplinar de Estudios Romanos, Madrid, Signifer, 2006, pp. 55-72.

Blecua, Alberto, «Introducción», Libro de Buen Amor, Madrid, Cátedra, 2010.

Cancionero de obras de burlas provocantes a risa, Valencia, Juan Viñao, 1519.

Cancionero de Poesías Varias: manuscrito 2803 de la Biblioteca Real de Madrid, ed. José J. Labrador Herraiz y Ralph A. Di Franco, Madrid, Patrimonio Nacional, 1989.

Cerezo, J. A., Literatura erótica en España. Repertorio de obras 1519-1936, Madrid, Ollero y Ramos, 2001.

Chamizo Domínguez, P. J. y M. Zawislawska, «Animal names used as insults and derogation in Polish and Spanish», Philologia Hispalensis, 20 (2006), pp. 137-174.

Criado de Val, Manuel, Diccionario de Español equívoco, Madrid, SGEL, 1981. 
Dens, Pierre, Tractatus selectus de vitiis et peccatis, Lovaina, L. J. Urban, 1777.

Díaz Fernández, J. Ignacio, «Compilar y desleír la poesía erótica de los Siglos de Oro: los cancioneros de Amancio Peratone», eHumanista, 15 (2010), pp. 302-320.

Dutton, Brian, El cancionero del siglo XV (c.1360-1520), 7 vols., Universidad de Salamanca, Salamanca, 1990.

Garrote Bernal, Gaspar y Alicia Gallego Zarzosa, «Español en Red 8.0: e-bibliografía y esquema para una historia de la literatura erótica (o sexual) española», AnMal Electrónica 29 (2010), pp. 253-290. <http://www.anmal.uma.es/numero29/ EspRED_8.pdf>.

Garrote Bernal, Gaspar, «Practicantes del ingenio sexual (siglos XIII-XVII)», AnMal Electrónica 32 (2012), pp. 235-275.

Giannelli, Lucio, «Las referencias a la música en la Lozana Andaluza», eHumanista, Volume 15 (2010), pp. 48-64.

Herrero, Juan, María Martínez Deyros y Zoraida Sánchez Mateos, «Aquel coger a oscuras a la dama»: mujeres en la poesía erótica del Siglo de Oro (Antología), Valladolid, Agilice Digital, 2018.

Horozco, Sebastián de, El Cancionero: introducción, edición crítica, notas, bibliografia y genealogía de Juan de Horozco, ed. Jack Weiner, Bern, Herbert Lang, 1975.

Huerta Calvo, Javier, «Cómico y femenil bureo (Del amor y las mujeres en los entremeses del Siglo de Oro)», Criticón, 24 (1983), pp. 5-68.

López de Úbeda, Francisco, La pícara Justina, ed. Antonio Rey Hazas, Madrid, Editora Nacional, 1977.

Marcos Durán, Domingo, Glosa sobre Lux bella, 1498, ed. David. G. Burton, Hispanic Seminary of Medieval Studies (Madison), 1992.

Martínez Garrido, E., «Breves consideraciones semánticas de género en torno al léxico “amoroso", a la retórica "erótica" y a las paremias misóginas», CFI, 12 (2005).

McGrady, D., «Notas sobre el enigma erótico, con especial referencia a los Cuarenta enigmas en lengua española», Criticón (1984), 27, pp. 71-108.

Montero Cartelle, E., «Censura y transmisión textual en Marcial», EClás, 78 (1976), pp. 169-178.

Montero Cartelle, E., «A linguaxe erótica no galego medieval: foder», en R. Álvarez Blanco et al. (ed.), A Lingua Galega: historia e actualidade. Actas do I Congreso Internacional, Santiago de Compostela, Consello da Cultura Galega-Instituto da Lingua Galega, 2004, III, pp. 625-636.

Muñoz Jiménez, M. J., «Defensa, traducciones e influencia de Marcial en las Poesías epigramatarias de Rafael J. de Crespo (Zaragoza 1837)», Cuadernos de filología clásica: Estudios latinos, 18 (2000), pp. 239-266.

Poesía erótica del Siglo de Oro, ed. P. Alzieu, R. Jammes e Y. Lissorgues, Barcelona, Crítica, 2000. 
Poesías varias de grandes ingenios españoles, ed. Joseff Alfay, Zaragoza, 1654.

Quevedo y Villegas, Francisco de, «Décimas contra Luis de Góngora», Obras poéticas completas, edición, introducción y notas de José Manuel Blecua, Barcelona, Planeta, 1990, pp. 1086.

Reynal, Vicente, El lenguaje erótico medieval a través del Arcipreste de Hita, Madrid, Playor, 1988.

Richards, L., « Juvenal et les galles de Cybèles », Revue de l'Histoire des Religions, 169 (1966).

Rodríguez-Moñino, Antonio, Suplemento al Cancionero General de Hernando del Castillo, Valencia, Castalia, 1959.

Rodríguez-Moñino, Antonio, Poesía y Cancioneros, Madrid, RAE, 1968.

Rubio Árquez, Marcial, «El Cancionero de obra de burlas provocantes a risa (Dutton 190B): orígenes y recepción», Revista de poética medieval, 28 (2014), pp. 359-375.

Rubio, Samuel, La polifonía clásica, Madrid, El Escorial, 1959.

Ruiz Sánchez, M., «Figuras del deseo. Arte de la variación en Marcial y en Ovidio», Cuadernos de filología clásica: Estudios latinos, 14 (1998), pp. 93-113.

Schatzmann Willvonseder, M., «Consideraciones acerca del erotismo en la investigación y en la poesía del siglo XVI», Dicenda, 2 (2003), pp. 281-300.

Serna, Melchor de la, Arte de amor, ed. Javier Blasco, Valladolid, Agilice Digital, 2016.

Ullman, S., Semántica. Introducción a la ciencia del significado, Madrid, Aguilar, 1972.

Varo Zafra, Juan, Alegoría y metafísica, Universidad de Granada, 2007. 